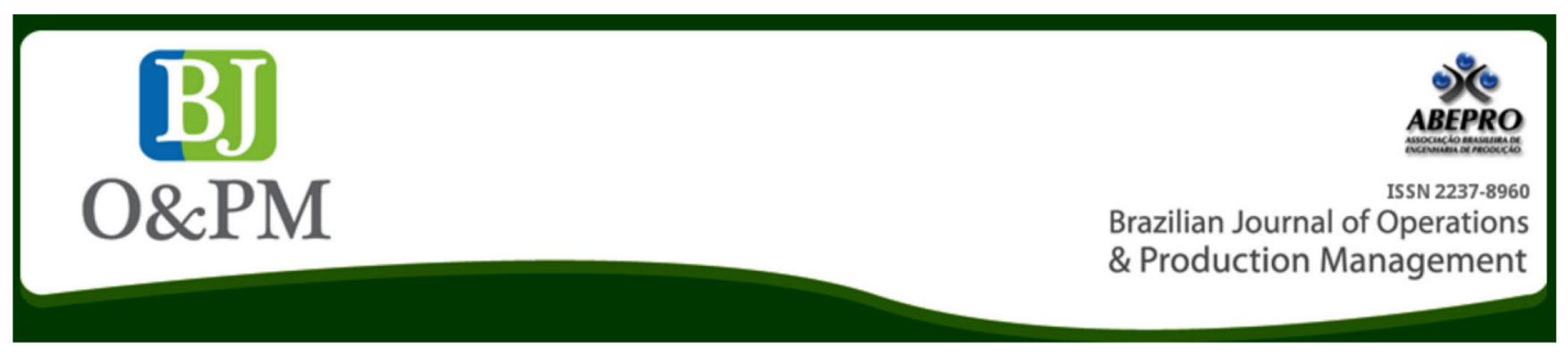

\title{
IMPROVEMENT BASED ON STANDARDIZED WORK: AN IMPLEMENTATION CASE STUDY
}

\author{
Julio Cesar Fin ${ }^{1}$, Gabriel Vidor ${ }^{1}$, Ivandro Cecconello ${ }^{1}$, Vanessa de Campos Machado ${ }^{1}$ \\ 1 University of Caxias do Sul
}

\begin{abstract}
Standardized work is an effective way for process improvement, specially when it is applied to manual tasks such as assembly lines. This tool is part of Toyota Production System and based on wastes reduction. Thus, the objectives were to implement standardized work in a medium chassis assembly line and measure the benefis from optimization of operators' tasks and movement through waste reduction. In order to achieve these results, a single case study was performed in a medium chassis assembly line that is part of a company in South Brazil. The steps involved: defining the object of study; time measurement and takt time definition; creating a production capacity sheet; defining the minimum number of operators and balancing the line; determining minimum work in process; defining the new layout; creating a standardized operations sheet and a standardized operations routine sheet; training and implementing standardized work; and verifying the results. Results show 36 minutes reduction in terms of assembly time and 200 meters reduction in terms of operators' movement on average. Other contributions regard the $9.6 \%$ reduction in terms of the assembly line downtime.
\end{abstract}




\section{INTRODUCTION}

Process improvement in organizations has been increasing, given the current market competitiveness reality. When market demand increases, companies need to control wastage, inventory and overproduction. Whereas low demand does not favor development, is even more important that resources be used effectively to keep organization's competitiveness. Hence, it is not enough to invest in technological innovations; however, it is also necessary to ensure space and operations optimization in the manufacturing floor.

This article aims to implement a standardized work method in an automotive company, as a way to identify waste and improve processes without major investments. Based on activities' mapping, workstations transfer, workforce task adjustment, and by improving inventories' location, it is possible to obtain significant improvements.

According to Monden (2015) and Dennis (2008) task standardization aims to guarantee that both material and human resources utilization are performing optimally. By thoroughly studying an activity and having the concepts clearly stated, it is possible to verify details, irregularities and wastes that, when added up, represent a big potencial to system improvement.

Standardized work method can be developed in several ways in manufacturing and services operations, not limited to the automotive industry. By applying the concept, tools, and techniques, the entire process can be improved, aiming better results. So, companies can seek the optimal process, considering the conditions and available resources.

Medium chassis market is a highly-pursued segment by car factories; thus, it is consequently extremely competitive. Due to a broad highway network and extensive urban centers in the Brazilian territory, there is always demand for this type of product. In order to ensure a bigger market share in this business field, companies need to constantly invest in improvements and updates. By standardizing assembly processes, it is possible to assure rework reduction and field problems, hence, guaranteeing greater reliability to the final customer and providing better overall results.

Standardized work increases productivity, besides reducing rework index. When dealing with manufacturing tasks that involve running multiple activities, this repeatability creates a logic sequence that reduces errors and waste probability.

\section{THEORETICAL BACKGROUND}

Companies all over the world are adopting the lean thinking that is based on the Toyota Production System (TPS)
(Morgan et Liker, 2006). By deeply studying the system, one can notice that its concepts are supported by two pillars: Just in Time and Autonomation. Since the beginning of TPS many tools were developed and can still be used to intensify the effects reached in differente industries. Among these tools, it is worth citing: Kanban system, Poka-yoke, 5S, factory layout, Single Minute Exchange of Die (SMED) and standardized work (Rodrigues, 2014).

Monden (2015) affirms that standardized work, as well as other TPS tools, is based on production time control activites and workforce balancing, quality improvement and lower production cost. By applying the tools proposed by this method, it is possible to create a stable system that can be applied to any production line in order to achieve constant and effective results.

\subsection{The production mechanism}

To study TPS, one needs to understand the production mechanism as a whole. It is reasonable to analyze what happens in production under two perspectives. By observing the material and services and ideas flow, thus, the process can be defined. Meanwhile, the work performed by the manpower, machines and equipment represents the operations. Both process and operations are connected; however, they must be analyzed separately as to accomplish system improvements (Antunes, 2008).

Process is the path travelled by raw material so it becomes a product, representing its flow from a raw material inventory to finished products. Meanwhile, operations regard the interferences made by workers to the material through the process. A deep process improvement analysis has to be performed prior to any attempt to enhance operations, in order to maximize production efficiency (Shingo, 1996).

There are two ways to improve processes. First, the product can be sharpened, and then the manufacturing processes are enhanced either through production engineering or technology application. The first stage investigates the best way to design the product, while sustaining quality and reducing production costs. The second stage pursues means for product manufacturing, resulting in machine speed variation and changes in temperature and tools (Shingo, 1996).

As addressed by Shingo (1996) and Antunes (2008), operation denotes the work performed on the material, and it can be classified in setup and principal.

Shingo (1996) declares that principal operations include essencial and incidental operations. Essential operations are described as stated below: (i) processing - products manufacturing and assembly; (ii) inspection - products quality in- 
spection; (iii) transportation - change in products' position on the shop floor; (iv) storage - keeping or storing parts and finished goods in shelves, boxes, etc. Incidental operations are run immediately before or after essential operations are performed, that is, the former requires the execution of the latter (Antunes Jr., 1994).

\subsection{Production process wastes}

Wastes can be primary: excess of personnel, inventory and equipment; or secondary, which is the consequence of primary wastes. One can consider that primary wastes are spread all over the factory and, consequently, lead to an increase in terms of admnistrative overall expenses. Regarding management, it is necessary to understand the wastes generated during the process, specially their causes. By tackling the primary wastes, secondary wastes will gradually decrease (Silva, 2008).

Regarding wastes elimination, it is mandatory to completely identify them according to what Shingo (1996) identified in the TPS and named "7 Wastes", as shown below: (i) overproduction; (ii) delay; (iii) transport; (iv) processing; (v) inventory; (vi) motion and; (vii) defective products.

The seven wastes are directly related to the production mechanism; therefore, they are related to process and operations.

\subsection{Standardized operation concept}

Standardized work is the safest, easiest, and most efficient way to perform a task; however, there is not only one way to do it. Standardized work has to be designed by the workers and be used as a basis for improvement, since the lack of stability and standardization could result in no production in a just in time system (Morgan et Liker, 2006). It is important to understand that activities are continually modifying themselves, since the process can and should always be improved (Dennis, 2008).

Standardized work goals are the pursuit of high productivity, through activities that are not hard, but efficient and active: to reach production line balance among all the process and to reduce production time and determine the minimum lot process, thus eliminating inventory and wastes (Monden, 2015).

\subsection{Standardized work elements}

To execute standardized work, it is mandatory that exact procedures are determined to be executed by each opera- tor, based on some elements. Among several authors there is an agreement in terms of the elements of standardized work, which are: takt time, work sequence and standardized inventory.

a) takt time is the amount of time needed to produce one unit of a product, it is given by the ratio between available time and production demand (OHNO, 1997);

b) work sequence is the order that tasks must be done by the operator in the determined cycle time (Monden, 2015);

c) standard in processstock is the minimum quantity of work in process needed so the operator can perform the process, avoiding work interruption while the machine runs (Dennis, 2008).

\subsection{Standardized work application method}

The method described by Monden (2015), along with some concepts declared by Dennis (2008) form the chosen basis to develop this article, since it is complete and provides details about the effective application of the presented concept. Thus, the main steps to apply standardized work in a company are: (i) set time to produce one unit; (ii) elaborate production capacity sheet; (iii) determine the standardized operations routine; (iv) prepare the standardized operations sheet and; ( $v$ ) train and verify the personnel.

\subsection{Determine the number of operators}

According to Antunes (2008), the definition of the number of operators is calculated by dividing the total manual time (all the manual operations performed in the cell or line) by the average output time between two units (takt time).

In assembly lines, most of the production times regard manual work; therefore, line capacity is highly connected to operators' training. This situation requires operators' flexibility so the system can ideally work (Antunes, 2008).

\subsection{Balance}

Shingo (1996) declares that time and motion studies drive $10 \%$ to $20 \%$ decrease in operation time. It can be done by improving motion and guaranteeing operational procedures such as parts placement, items alignment, and easy access to components and fixed positioning of components.

Assembling processes does not always occur in an assembly line, since they can also be the combination of two or 
more manufactured or purchased components in one assembly. Given that assembly time is longer than the individual manufacturing time for each component, the amount of work should be divided in working stations, and each working station should be determined and balanced (Salvendy, 1992).

Salvendy (1992) defines a precedence diagram, in which the assembly process is arranged in tasks to form a sequence, that is, for one task to be performed it is mandatory that the previous tasks have already been completed. Along the sequence of tasks, the takt time and minimum number of stations have to be determined.

\section{METHOD}

Based upon the theoretical study conducted in the previous session, an implementation flow was planned, containing the stages to be followed so that the standardized work is implemented in the medium chassis assembly line, as shown in Figure 1.

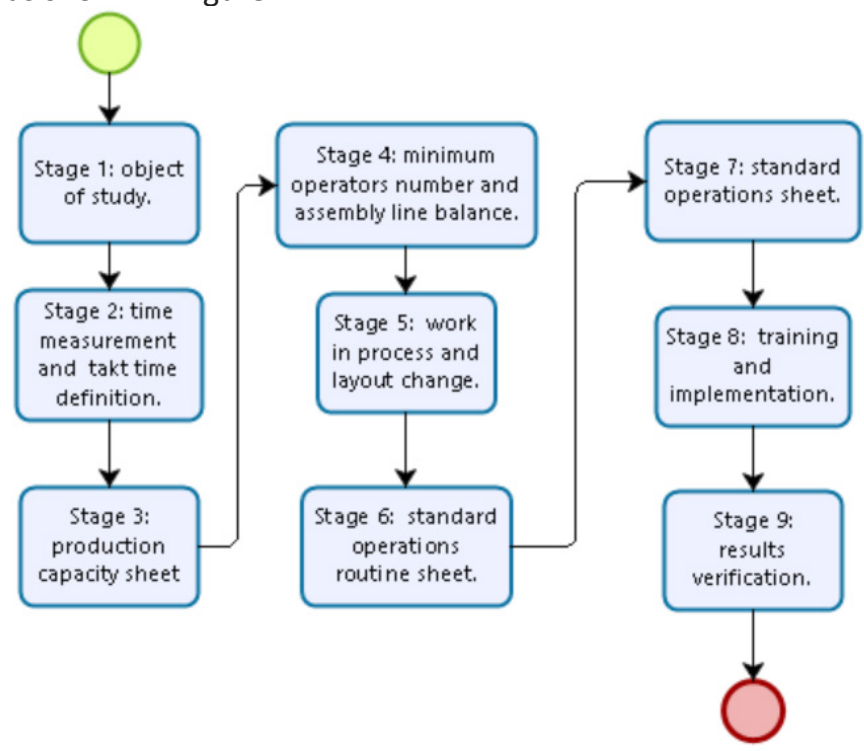

Figure 1. Standardized work implementation flow Source: the authors (2016).

During stage 1 all data regarding product and process were collected, as well as information on demand forecasting and production capacity.

Stage 2 consisted of the time measurement of each task performed in the assembly line, as to double-check stablished time. Assembly line's takt time is defined based on data on monthly production and assembly line's operation time.
The production capacity sheet was elaborated during stage 3 , and includes assembly line processes' execution order, processes' names, main machines and devices used in the processes, workstations' cycle time and production capacity.

The operations were distributed along the steps during stage 4 , taking into consideration takt time as the limit to add operations in each step, as well as constrains in terms of equipment, personnel, and storage area.

The adjustments proposed on stage 5 considered layout constraints, such as available area, products dimensions and hallways arrangement. During this stage, the best distribution of parts storage along the assembly process was implemented, in order to reduce motion and inventory wastes.

For stages 6 and 7, the Standardized Operation Routine Sheets were developed, containing the sequence of tasks the operator must follow, as well as the time allotted to perform each task; and the Standardized Operations Sheet, that consists of the workstation layout, the standard-in-processstock and important items, and the requirements regarding quality and safety.

After the documents specified in the previous stages were approved, stage 8 required the training of the maximum number of operators in the proposed tasks, so they would be able to keep the standardized work even when there are absences or employee turnover.

After finalizing stages 1 to 8 , the standardized work method was already internalized by the operators, so the assembly line performance was constantly checked, as to verify if the steps proposed were followed and operations standard was maintained.

\section{CASE STUDY}

\subsection{Object of study}

This research was applied to a medium chassis assembly line in a company in South Brazil. The company is part of the automotive sector, since it manufactures tractors, trucks, chassis for buses, utility vehicles, motors, and generator sets. The assembly line performance was measured before and after the implementation of the standardized work method to check if the goals were achieved. The chassis model assembled in the assembly line is shown in Figure 2. 


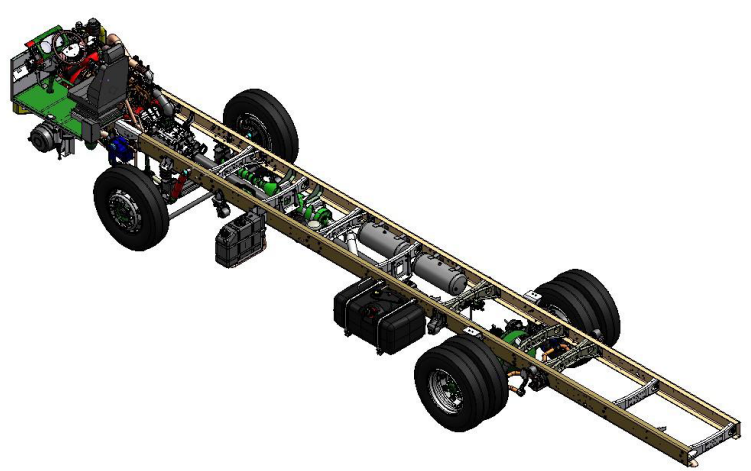

Figure 2. 3D illustration of a finished medium chassis. Source: company's collection (2015).

The assembly cell is line-shaped, dividide in seven stages, consisting of parts pre-assemblies in areas next to the main assembly line. Regular products' parts inventories are located in shelves beside each stage, while the items with greater demand and surplus invetory are held in specific logistic storage rooms.

\subsection{Timekeeping and takt time definition}

Initially, each operation was clocked, and all the assembly line operation time periods were compared, updated and registered in the information system. The main elements clocked were: assembler motion to the parts' inventory or to the tools' cart, position and assemble parts.

Considering only complete products assembled monthly that every month is 20 business days long, and the assembly line's daily operation time is 528 minutes long, takt time can be determined according to Formula 1:

\section{Assembly line takt time $=(528$ minutes $) /(2.08$ products $/$} day) $=254.2$ minutes $/$ product

\subsection{Production Capacity Sheet}

In each stage of the assembly line several operations are performed, as well as many actitivities within each operation. In order to develop the Production Capacity Sheet, each stage's capacity was considered, as shown in Table 1.

\subsection{Operators number and balancing}

In order to determine the number of operators in the assembly line, it is necessary to consider the time measured and the fatigue factor in each stage of the line individually, after divide this result by the takt time. When adding up the found values, the minimum theoretical number of operators in the assembly line is 7.34. However, there are some aspects to take into consideration before determining the ideal number of operators. The assembly line has a logic sequence that should be followed for its operations. This sequence is determined by constraints on some machines and fixed devices in the assembly line, parts that must be assembled before others, and the continuity among the vehicle's systems.

The results shown on table 2 resulted from the topics mentioned above and by using the instructions previously provided to calculate de number of operators.

Table 1. Production Capacity Sheet

\begin{tabular}{|c|c|c|c|c|}
\hline \multicolumn{3}{|c|}{ Production capacity sheet } & \multirow{2}{*}{$\begin{array}{c}\text { Product } \\
\text { Responsible } \\
\begin{array}{c}\text { Production time for one } \\
\text { unit (minutes) }\end{array} \\
\end{array}$} & \multirow{2}{*}{$\begin{array}{c}\text { Medium chassis } \\
\text { Process engineering } \\
\begin{array}{c}\text { Production capacity } 528 \\
\text { min. (chassis) }\end{array}\end{array}$} \\
\hline \begin{tabular}{|c|}
$\begin{array}{c}\text { Process } \\
\text { order }\end{array}$ \\
\end{tabular} & Process name & Main machines/devices used & & \\
\hline $1^{\text {st }}$ stage & Chassis frame assembly & $\begin{array}{c}\text { Crane, chassis engraver, tightening } \\
\text { table, and controlled torque machines. }\end{array}$ & 273.07 & 1.93 \\
\hline $2^{\text {nd }}$ stage & Axis coupling & Crane and controlled torque machines. & 199.31 & 2.65 \\
\hline $3^{\text {rd }}$ stage & Chassis frame panting & Paint booth. & 77.87 & 6.78 \\
\hline $4^{\text {th }}$ stage & Break system assembly & Electrice screwdriver. & 225.64 & 2.34 \\
\hline $5^{\text {th }}$ stage & $\begin{array}{l}\text { Engine, radiator and drive wheel system } \\
\text { coupling }\end{array}$ & Crane and controlled torque machines. & 235.21 & 2.24 \\
\hline $6^{\text {th }}$ stage & $\begin{array}{c}\text { Eletric system, exhaust, wheels and } \\
\text { plataform assembly }\end{array}$ & Crane and controlled torque machines. & 475.09 & 1.11 \\
\hline $7^{\text {th }}$ stage & Hose, tubes, and fluid fueling assembly & $\begin{array}{c}\text { Controlled torque machines and } \\
\text { fueling devices. }\end{array}$ & 269.04 & 1.96 \\
\hline
\end{tabular}


Table 2. Operators number

\begin{tabular}{|l|c|c|}
\hline \multirow{2}{*}{ Stage } & \multicolumn{2}{|c|}{ Medium chassis - Operators number } \\
\cline { 2 - 3 } & Theoretical number & Considering constraints \\
\hline $1^{\text {st }}$ stage & 1.51 & 2 \\
\hline $2^{\text {nd }}$ stage & 0.78 & 2 \\
\hline $3^{\text {rd }}$ stage & 0.31 & 1 \\
\hline $4^{\text {th }}$ stage & 0.89 & 1 \\
\hline $5^{\text {th }}$ stage & 0.93 & 2 \\
\hline $6^{\text {th }}$ stage & 1.87 & 2 \\
\hline $7^{\text {th }}$ stage & 1.06 & 1 \\
\hline TOTAL & 7.34 & 11 \\
\hline
\end{tabular}

Source: the auhtors (2015).

The process' constraints decreased operations' balance efficiency, since it is required to increase the human resources in the execution of several activities. Formula 2 below presents the formula to determine balance efficiency.

\section{Project efficiency $=7,34 / 11 \times 100=66,73 \%$}

Formula 2. Balance efficiency

\subsection{Work in process and layout change}

Each stage has a designated area that is 15 meters long and seven meters wide in order to fit the product that is assembled, as well as enough space for operators to walk, and a storage area for parts that are used during the process.
These subassemblies are the closest to the place where they will be assembled as possible.

The subassembly processes are next to the assembly line so they are assembled in the products afterwards. In order to control the amount of subassembly sets, along with the process instruction sheet, a controling sheet is distributed for each subassembly at the beginning of the shift. Therefore, the assemblers will not preassemble more sets than it is daily required.

As to promote all the changes in the assembly line, the continuous improvement tool kaizen was used, since it is the basis for TPS. Through this tool, all the actions required to adjust the assembly line to the proposed model were planned and executed in one week. The main activities performed in the assembly line are listed below:

a) 58 obsolete items were withdrawn from the assembly line;

b) 44 boxes of parts were adjusted to fit the changes in their placement;

c) high demand items and the heaviest parts were moved closer to the the assembly line, so it is easier to access them and supply them to the line by using forklifts;

d) a central for bateries for the electric screwdrivers was created;

e) development, adjustment, and improvement of devices and tools' carts.

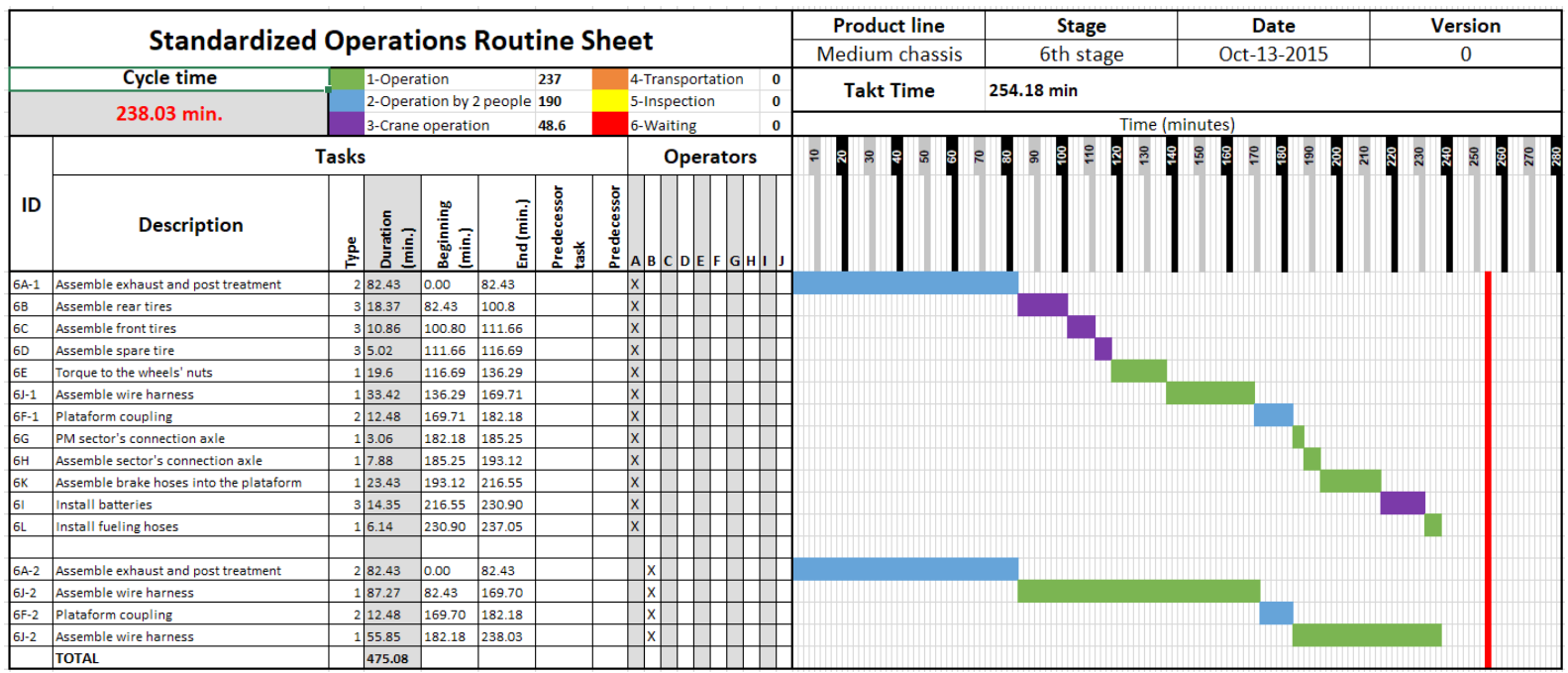

Figure 3. Example of a Standardized Operations Routine Sheet Source: the authors (2015). 
Brazilian Journal of Operations \& Production Management

Volume 14, Número 3, 2017, pp. 388-395

DOI: 10.14488/BJOPM.2017.v14.n3.a12

\subsection{Standardized Operations Routine Sheet}

For each workstation, a Standardized Operations Routine Sheet was elaborated as shown in Figure 3. In order to develop this sheet, six types of activities were defined: operation, operation by two people, operation by crane, transportation, inspection and waiting time. This distinction allows visualizing the charts and verifying that the crane is the resource with the biggest usage limitation, and the activities that must be done at the same time, when there is more than one operator at the same stage.

By achieving the optimal line balance among the tasks in all the stages, it is not necessary to have standard-in-process-stock which can be considered the ideal process.

\subsection{Standardized Operation Sheet}

The Standardized Operation Sheet was developed and made available at each workstation, as well as the Standardized Operation Routine Sheet. This sheet describes safety and quality items, work in process, and operators' optimal movements at their workstations in order to achieve better results, as shown on Figure 4.

This sheet shows the layout of the stage analyzed, so it is easier for the operator to understand the tasks' order and movements to be done by visualizing the layout. It also makes possible to verify whether the taks are done the best way possible, and it helps when there are new operators to be trained.

\subsection{Training and implementation}

The successful implementation of the lean thinking depends on training programs after the introduction of TPS philosophy. Thus, a meeting with all the operators and the specialized assembler was organized so the project was proposed and specified, as well as the method's objectives and its benefits. The importance of performing all the activities in the established order was explained, as a requirement to achieve the best resources' use and enhance workforce labor.

The Standardized Operation Routine Sheet and the Standardized Operation Sheet were showed to the operators and the meaning of the information on them was explained. The method's objective was enlightend by showing the operators that all the assembly processes would be easier and productivity would be improved after the implementation. The importance of using and paying attention to these two sheets together was highlighted, since the information on them is complementary.

The operators easily accepted the method proposed, because they realized this technique aims to make everyone's activities easier in the workstations. During the training, operators' questions and doubts regarding the material presented were answered, and their suggestions for future improvements were recorded.

After the training, all the material developed was released along the assembly line. First, the sheets were introduced to the line's supervisor and specialized assembler, then they verified the activities order and the established time, so they approved the document. Parts and tools' positions were double-checked,

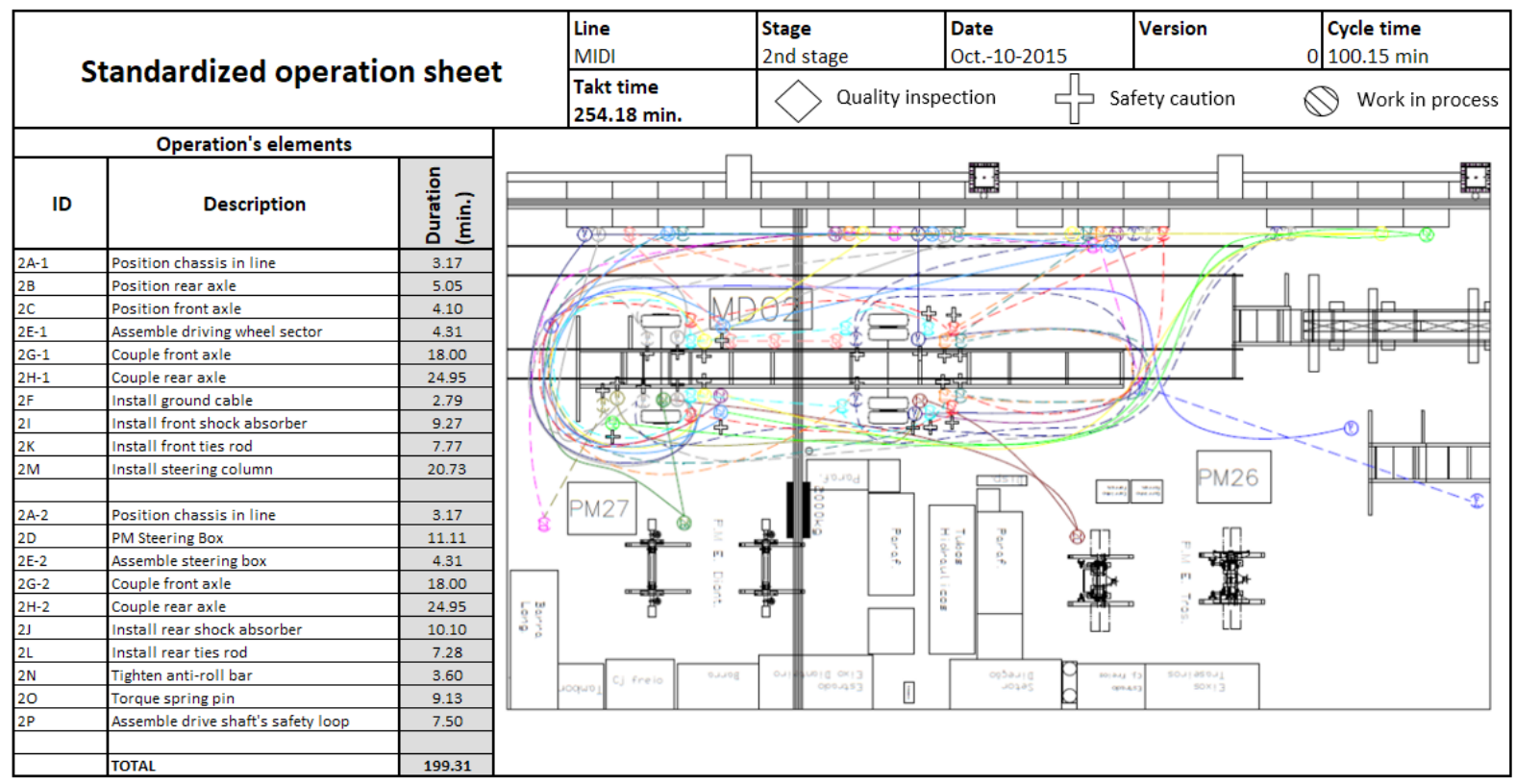

Figure 4. Example of Standardized Operation Sheet Source: the authors (2015). 
to insure operators' minimum movement when searching for them during the assembly process.

To maintain the standardized work, it is important to verify periodically any changes in the process that may modify the operations performed. The company has to consider and make feasible product modifications, process improvements, purchase new tools and devices, so that process data and personnel involved are always up to date. The process engineering department is held responsible for conducting this activity, along with the assembly line staff and other departments that may be involved, such as quality and supply chain departments.

\subsection{Results' verification}

The results were verified after one month the operation started using the new method, so the operators were used to the new process, to the new parts' places, and had already achieved a regular work pace.

The assembly time was decreased by 36 minutes when compared to the situation prior to the standardized work implementation. By transfering some activities to subassembly stages next to the line border and moving parts to the inventory, operators' movements were optimized, reducing 200 meters on average and 5 stoppages to look for parts and tools for each vehicle assembled. Thus, it is possible to affirm that the focus of standardized work was kept during its implementation.

Therefore, the proposal of this study was legitimate, since positive results were achieve as described above. Moreover, standardized work is based on people's commitment, so the assembly line staff will continue working towards process' continuous improvement, eliminating failures and wastes and pursuing manufacturing excellence.

\section{CONCLUSION}

The stages proposed to apply standardized work method in the assembly line were effective regarding the achievement of the goals established. The general objective presented was accomplished, since all the stages proposed were completed and the method proposed was implemented.

The Standardized Operations Routine Sheet and the Standardized Operations Sheet granted tasks order standardization. In order to complete stage 4 , the minimum number of operators and operations' balancing was determined by dividing the workload, so the activities could be done within the takt time established, and taking the constraints into consideration. By adjusting the layout and determining minimum work in process inventory, the wastes found in the process were reduced, ben- efiting the supplying process performed by the logistics department. And the entire assembly line was better settled.

The way the Standardized Operation Routine Sheet and the Standardized Operation Sheet were developed assists visual management, since it is possible to verify activities' sequence, and identify potential improvements and problems easily.

Nowadays, the greater constraint the assembly line faces is a substantial lower demand, compared to the assembly line's production capacity due to the economical crisis that is harming the entire industrial sector.

Among the results, it is worth citing that the cycle time was reduced by $15 \%$, operators' movement was decreased by $34.5 \%$, and downtime was reduced by $9.6 \%$. These results attest that the method employed is robust and represents real improvement opportunities.

\section{REFERENCES}

Antunes, J. (2008) Sistemas de produção: conceitos e práticas para projeto e gestão da produção enxuta. Porto Alegre: Bookman.

Antunes Junior, J. A. V. (1994) O mecanismo da função de produção: a análise dos sistemas produtivos do ponto-de-vista de uma rede de processos e operações. Produção, Vol. 4, No. 1, pp. 33-46. Available at: <http://www.scielo.br/pdf/prod/v4n1/ v4n1a03.pdf>. Acess: 10th April, 2017.

Dennis, P. (2008) Produção lean simplificada: Um guia para entender o sistema de produção mais poderoso do mundo. Porto Alegre: Bookman.

Monden, Y. (2015) Sistema Toyota de Produção: uma abordagem integrada ao just in time. Porto Alegre: Bookman.

Morgan, J.M. et Liker, J.K. 2006. The Toyota product development system: Integrating people, processes, and technology. NY: Productivity Press

Ohno, T. (1997) Sistema Toyota de Produção: além da produção em larga escala. Porto Alegre: Bookman.

Rodrigues, M. V. (2014) Entendendo, Aprendendo e Desenvolvendo Sistemas de Produção Lean Manufacturing. Rio de Janeiro: Elsevier.

Salvendy, G. (1992) Handbook of industrial engineering. 2.ed. New York, US: Institute of Industrial Engineers.

Shingo, S. (1996) O Sistema Toyota de Produção: do ponto de vista da engenharia de produção. 2. ed. Porto Alegre: Bookman.

Silva, E. Z. (2008) Um Modelo de Guia para a Preparação da Implementação da Produção Enxuta Baseado na Aprendizagem Organizacional, tese (Doutorado em Engenharia), Universidade Federal do Rio Grande do Sul, Porto Alegre. 